\title{
A importância da mediação social na investigação do conceito de carga elétrica no Ensino de Física
}

\author{
The importance of social mediation in investigating the concept of \\ electric load in teaching of physics
}

Graciela Paz Meggiolaro (gracipmegg@ gmail.com)

Universidade Federal da Fronteira Sul (UFFS)

Agostinho Serrano (agostinho.serrano@ulbra.br)

Universidade Luterana do Brasil (ULBRA)

\begin{abstract}
Resumo: Neste trabalho buscamos investigar/identificar quais mecanismos externos de mediação de acordo com a Teoria da Mediação Cognitiva (TMC), são determinantes na aprendizagem de carga elétrica em alunos da disciplina de Física Geral III, por intermédio de uma simulação computacional no Software GeoGebra. Adotamos o referencial teórico da Teoria da Mediação Cognitiva (TMC) em relação ao mecanismo externo de mediação e a Teoria dos Campos Conceituais (TCC) com as situaçõesproblema. As análises dos dados coletados foram através dos gestos descritivos e imagens mentais, que nos deram indícios de que o uso articulado dos mecanismos externos de mediação psicofísico, cultural, social e hipercultural revelou-se importante, porém a mediação social sobressaiu-se na aprendizagem do conceito de carga elétrica, apontada por quatro alunos.
\end{abstract}

Palavras-chave: Carga elétrica; Teoria da Mediação Cognitiva; Teoria dos Campos Conceituais.

Abstract: In this work we seek to investigate/identify which external mediation mechanisms according to the Theory of Cognitive Mediation (MCT), are determinants in the learning of electric charge in students of the discipline of General Physics III, through a computer simulation in the GeoGebra Software. We adopted the theoretical framework of Cognitive Mediation Theory (MCT) in relation to the external mechanism of mediation and the Conceptual Fields Theory (TCC) with problem situations. The analyzes of the collected data were through descriptive gestures and mental images, which gave us clues that the articulated use of external mechanisms of psychophysical, cultural, social and hypercultural mediation proved to be important, but social mediation stood out in the learning process. Electric charge concept pointed by four students.

Keywords: Electric charge; Cognitive Mediation Theory; Theory of Conceptual Field.

Recebido em: $12 / 01 / 2020$

Aceito em: $31 / 08 / 2020$ 


\section{INTRODUÇÃOO}

O estudo de eletromagnetismo é fundamental para todos os ramos da Física, sendo a combinação de fenômenos elétricos e magnéticos. Dentre as diversas implicações do eletromagnetismo, podemos mencionar, por exemplo, que a corrente elétrica produz efeitos magnéticos, e ambas associadas, produzem ondas eletromagnéticas, ondas de rádio, televisão, micro-ondas, etc.

Justifica-se que o estudo de fenômenos físicos relacionados ao eletromagnetismo é mais abstrato do que os fenômenos mecânicos (LOPEZ; SILVA, 2015). No entanto, o entendimento dos alunos sobre os fenômenos físicos envolvidos ainda causa um desconforto, devido a alguns elementos complexos de visualização e a dificuldade que os alunos possuem em criar e usar representações da aplicação da física (GIRE, 2014; DA SILVA et al. 2020).

Este ramo é tão abstrato que temos vários trabalhos que apontam as dificuldades que os alunos possuem, como os de Furió; Guisasola e Almudí (2004), Furió e Guisasola (1998; 2001), Furió et al. (2002), Gagnon (2011), Guisasola et al. (2008), Guisasola e Furió (1998), Martin e Solbes (2001), Rocha e Andrade Neto (2013), Santos, Santos e Fraga (2002) e Lopez e Silva (2015).

Em nível mundial, existem trabalhos dentro da área de Ensino de Física que são ubíquos em qualquer revisão bibliográfica voltada ao aprendizado de eletromagnetismo, mencionamos, por exemplo: Dori e Belcher (2005), Gupta, Hammer e Redish (2010), Periago e Bohigas (2005), Baser e Geban (2007).

Sobretudo, torna-se indispensável o estudo de eletrostática não apenas como memorização de métodos ou equações, mas, sim, com propostas de ensino que possam proporcionar ao aluno a sustentação teórica necessária para confrontar suas concepções iniciais na busca pela compreensão do ambiente que o cerca. Para Vergnaud (1990) as situações é que dão sentido ao conceito. E o conceito torna-se significativo através de uma variedade de situações. Para tanto em nossa visão as situações precisam ser estabelecidas e incorporadas por mecanismos externos, dando sentido aos conceitos de carga elétrica, campo elétrico e força elétrica.

Em conformidade com o acima exposto, é essencial analisarmos como ocorre a evolução da conceitualização dos alunos ao longo do experimento, não apontando se estão corretos ou errados, mas, sim, analisando como esses conceitos se estabelecem por meio dos mecanismos externos. Dessa forma, o objetivo deste trabalho é 
investigar/identificar quais mecanismos externos de mediação de acordo com a Teoria da Mediação Cognitiva (TMC), são determinantes na aprendizagem de carga elétrica em alunos da disciplina de Física Geral III.

A Teoria da Mediação Cognitiva - TMC - permite explicar a interação entre a estrutura cognitiva do sujeito e o mecanismo externo de mediação, mediante representações mentais. $\mathrm{O}$ cérebro cria competências específicas para comunicar-se com este mecanismo, propiciando a aquisição de conhecimentos (SOUZA, 2004). A cognição extracerebral é uma mediação que depende das estruturas externas, as quais complementam o processamento de informações realizado pelo cérebro (SOUZA et al., 2012).

\section{REFERENCIAL TEÓRICO}

A ligação entre a Teoria da Mediação Cognitiva e a Teoria dos Campos Conceituais está nas relações entre o entrelaçamento do mecanismo externo de mediação com as situações-problema, tornando um conceito significativo, onde o sentido é uma relação que os alunos fazem com as situações por meio de mecanismo externo de mediação. Além da Teoria dos Campos Conceituais, que discute a importância das situações para o aprendizado, também destacamos o papel das mediações externas, tais como simulações, como discutidos pela Teoria da Mediação Cognitiva.

A mediação cognitiva, para Souza (2004), ocorre relacionando os processos internos e externos à estrutura cognitiva por intermédio dos drivers, mediante os conhecimentos individuais e o acesso e uso de mecanismos externos, possibilitando a aquisição de conhecimentos e desenvolvimento da estrutura cognitiva. E, existem quatro níveis de mediação, de acordo com a TMC: a Mediação Psicofísica; a Mediação Social, a Mediação Cultural, e a Mediação Hipercultural.

Gérard Vergnaud, em sua Teoria dos Campos Conceituais, aponta que a chave para a capacidade cognitiva reside em um conjunto de habilidades que incluem não apenas o conhecimento técnico-científico, mas, também, o conhecimento informal e os aspectos de gesto, linguagem, comunicação, sociabilidade e competência afetiva. Existiriam três níveis de organização, sendo eles os conceitos, os esquemas e as competências (SOUZA, 2004).

Recebido em: 12/01/2020

Aceito em: $31 / 08 / 2020$ 
$\mathrm{Na}$ Teoria dos Campos Conceituais, o desenvolvimento cognitivo depende fortemente da situação e da conceitualização específicas. Para Vergnaud (1990, p. 52), "o saber se forma a partir de problemas para resolver, quer dizer, de situações para dominar. [...] toda situação na qual é preciso descobrir relações, desenvolver atividades de exploração, de hipótese e de verificação, para produzir uma solução”.

Os conceitos "são representações mentais das relações possíveis entre o mundo exterior e os próprios comportamentos que surgem a partir dos mecanismos adaptativos de assimilação e acomodação [...]" (SOUZA, 2004, p. 114). Os Esquemas são "um conjunto de ações coordenadas, integradas por regras ou conceitos, que é aplicável com sucesso para determinadas categorias de problemas e contextos (algoritmos)" (SOUZA, 2004, p. 114). As Competências são um conjunto de esquemas bem organizados; são “[...] repertórios amplos de ações que possibilitam ao indivíduo enfrentar classes de situações (ou grupos de classes) e suas possíveis variações” (SOUZA, 2004, p. 114).

A Teoria dos Campos Conceituais produz ações de grande tamanho e complexidade, em que se promove a capacidade de lidar com distintas situações e esses contextos são representados sob a forma de conceitos e organizados em esquemas e competências (SOUZA, 2004). Segundo a TMC, “o desenvolvimento cognitivo envolve a interação de um indivíduo com objetos e sistemas que tenham capacidade de realizar computações, sendo um processo que envolve o surgimento simultâneo dos mecanismos internos e externos de mediação" (SOUZA, 2004, p. 116). O indivíduo não apenas aloca os mesmos recursos computacionais, como também ganha novos conceitos, metáforas e operações lógicas, expandindo significativamente a sua capacidade mental.

Vergnaud (1990) definiu que em um campo conceitual existe uma variedade de situações em que os conhecimentos dos alunos são moldados pelas situações que dão sentido aos conceitos e aos procedimentos que queremos que os alunos aprendam, e que toda situação complexa pode ser analisada com uma combinação de tarefas, onde os processos cognitivos e as respostas do sujeito são função das situações com as quais é confrontado.

A mediação cognitiva, para Souza (2004), ocorre relacionando os processos internos e externos à estrutura cognitiva por intermédio dos drivers, mediante os conhecimentos individuais e o acesso e uso de mecanismos externos, possibilitando a aquisição de conhecimentos e desenvolvimento da estrutura cognitiva. E, existem 
quatro níveis de mediação, de acordo com a TMC: a Mediação Psicofísica; a Mediação Social, a Mediação Cultural, e a Mediação Hipercultural.

A ligação entre a Teoria da Mediação Cognitiva e a Teoria dos Campos Conceituais está nas relações entre o entrelaçamento do mecanismo externo de mediação com as situações-problema, tornando um conceito significativo, onde o sentido é uma relação que os alunos fazem com as situações por meio de mecanismo externo de mediação. Além da Teoria dos Campos Conceituais, que discute a importância das situações para o aprendizado, também destacamos o papel das mediações externas, tais como simulações, como discutidos pela Teoria da Mediação Cognitiva.

\section{ABORDAGEM METODOLÓGICA}

Caracterizamos a pesquisa como sendo de natureza qualitativa no Ensino de Física, devido à produção de dados por intermédio de entrevistas transcritas, palavras, figuras e formas de documentos. A finalidade da pesquisa qualitativa é documentar, em detalhes, os eventos diários e identificar o que esses eventos significam para os participantes e para as pessoas que presenciam os eventos (ERICKSON, 1998). O estudo foi realizado no primeiro semestre de 2017, com cinco alunos do curso de graduação em Engenharia Civil.

Para a obtenção de dados, utilizamos para a pesquisa o pré e o pós-teste individual com situações-problema relacionadas à simulação e entrevistas na tentativa de avaliar as possíveis alterações que possam ter ocorrido na estrutura cognitiva do aluno. Detalhamos a seguir os quatro momentos da produção de dados:

Pré-teste: realizado individualmente com quatro situações-problemas abertas, envolvendo conceitos de campo elétrico antes da simulação computacional, visando investigar o conhecimento inicial dos alunos acerca dos conceitos relacionados ao campo conceitual da eletrostática.

Guia de Simulação computacional: $O$ guia de atividade tinha a pretensão de orientar as duplas no desenvolvimento da simulação no GeoGebra, referente a campo elétrico. A atividade foi fundamentada no método P.O.E. (Predict-Observe-Explain), que significa predizer-observar-explicar (TAO; GUNSTONE, 1999).

Simulação: A simulação escolhida está disponível em < https://www.geogebra.org/m/eHyU8ZmU> conforme a figura 1, refere-se ao conteúdo da Eletrostática que é o estudo de cargas em repouso. Nesta simulação é possível

Recebido em: 12/01/2020

Aceito em: $31 / 08 / 2020$ 
visualizar o vetor campo elétrico gerado pelas cargas, as quais indicam a intensidade e a direção do campo.

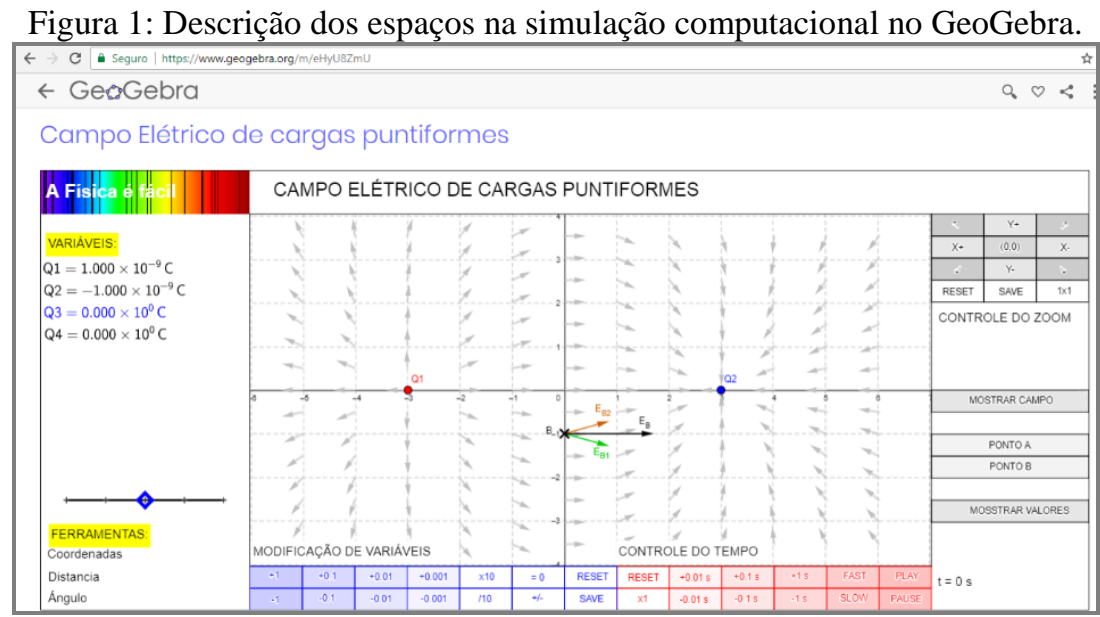

Fonte: https://www.geogebra.org/m/eHyU8ZmU

Pós-teste: as situações-problema eram semelhantes àquelas do pré-teste, porém, nosso objetivo estava em encontrar evidências na construção e/ou modificados de imagens mentais associada ao uso de diferentes mecanismos externos de mediação no domínio das situações-problema.

Entrevista: Foram gravadas e eram individuais, utilizamos a técnica Report Aloud (TREVISAN et al., 2019), em que o estudante reporta o seu processo de pensamento enquanto responde às questões, associadas à análise de gestos descritivos. Ramos (2015), Wolff (2015), Trevisan (2016), Veloso (2017), Meggiolaro (2019) e Trevisan et al. (2019) utilizaram a Técnica Report Aloud, e observaram que mesmo com intervalo de alguns dias entre a atividade com a resolução das questões e a realização da entrevista, o aluno lembrava dos desencadeamentos que aplicou na atividade.

Transcrição e gestos: Cada aluno foi renomeado, a fim de identificá-los e preservar seus nomes originais. As entrevistas foram transcritas e as imagens dos gestos foram codificados.

Com a intenção de analisar a linguagem verbal presente na produção de dados, utilizamos a Análise Textual Discursiva proposta por Moraes e Galiazzi (2007), que envolve identificar e isolar enunciados dos materiais submetidos à análise, categorizar esses enunciados e produzir textos, integrando neles descrição e interpretação, utilizando como base de sua construção o sistema de categorias construído. 
E Análise Gestual Descritiva em relação aos gestos dos alunos, baseada em Mornaghan e Clement (1999) e Clement, Stephens (2010), no qual afirmam que quando os alunos utilizam os movimentos das mãos estão sugerindo imagens dinâmicas de simulações mentais durante a resolução de problemas de movimento relativo.

\title{
4. ANALISE E DISCUSSÃO DOS RESULTADOS
}

Apontaremos os alunos separadamente, uma vez que, cada um evidenciou um ou mais mecanismo externo de mediação para o mesmo conceito discutido. $\mathrm{O}$ aluno 5, cita sobre as cargas serem positivas ou negativas:

\begin{abstract}
Aluno 5: Carga, eu penso, um elétron ou uma carga que tem uma... Um positivo e negativo, tem sentido de... Carga, para mim, é... Pode ser assim. Carga, para mim, são três tipos: a positiva, a negativa e a nula, não é? Daí porque eu sei que a positiva doa (Figura 2I) e que a negativa recebe (Figura 2II); a nula é quando tem o mesmo nível, mesmo número de cátions e íons.
\end{abstract}

Figura 2: Aluno 5: (I) Gesto \#CEP: Carga Elétrica Positiva; (II) Gesto \#CEN: Carga Elétrica Negativa.

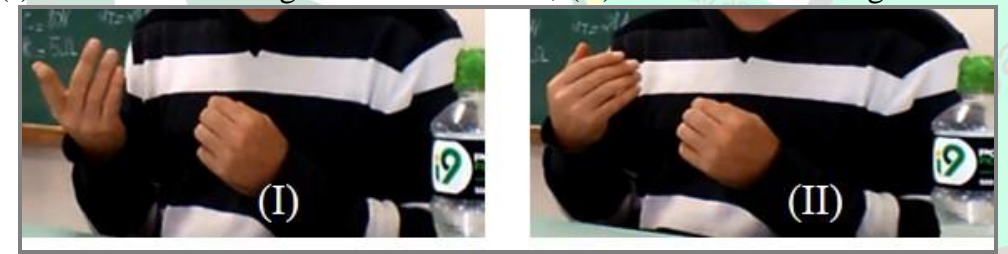

Fonte: Meggiolaro (2019).

(I)\#CEP: Carga Elétrica Positiva: demonstra, mediante o movimento dos dedos, que as linhas de campo são direcionadas para fora e que se repelem.

(II) \#CEN: Carga Elétrica Negativa: demonstra, mediante o movimento dos dedos para dentro, que cargas negativas se atraem.

Quando questionado sobre este conceito de carga ser positiva, negativa ou nula, o aluno refere-se: "da aula de química, mas daí, eu usei um pouco o conhecimento de química para fazer isso daqui, aqui”. Neste fragmento, percebemos que o conceito de carga foi estabelecido inicialmente na aula química, possivelmente sendo uma mediação social devido a essa interação e indícios da mediação hipercultural pelo estudo em vídeos "Ah é que também olho vídeos, então já olhei bastante vídeo de bomba atômica, de bombas assim", no YouTube.

Ao utilizar exclusivamente o discurso verbal do aluno 5, podemos enunciar seu teorema-em-ação para carga como sendo "cargas podem ser positivas, negativas ou nulas, a positiva doa e a negativa recebe, e a nula tem o mesmo número de cátions e

Recebido em: 12/01/2020

Aceito em: $31 / 08 / 2020$ 
íons". Isso evoca no leitor a imagem de que o estudante associa predominantemente carga à situações de química.

Contudo, ao incluir a análise gestual, considerando o discurso verbo-gestual completo, tal como descrito em Trevisan et al., (2019), percebe-se que o aluno utiliza gestos que indicam imagens de linhas de campo em torno de uma carga. Considerando o discurso verbo-gestual poderia ser enunciado como "Cargas podem ser positivas - cujas linhas de campo se dirigem para fora da carga - podem ser negativas - com linhas de campo que se dirigem para dentro da carga - ou nulas, com mesmo número iônico". O conceito-em-ação de carga está, naturalmente portanto, relacionada à um ponto com linhas de campo e considerações de conceitos de química.

Para a aluna 6, carga elétrica é como um pontinho (Figura 3I): "ele é redondinho, pequeninho, redondinho”. Ela realiza gestos que refere-se a imagem mental representando algo pequeno. Em seguida, fez associação com a carga de um caminhão:

\footnotetext{
Aluna 6: por exemplo, qual a carga de um caminhão?" (Figura 3II); “é o peso do caminhão! A carga que o caminhão transporta, o peso, é um valor que ele tem atribuído. Uma carga, uma partícula, é o pesinho pequeninho que ela tem" (Figura 3III).
}

Por meio de gestos que refere-se a imagem mental de um deslocamento do caminhão em cima da mesa. Essa comparação da carga elétrica com um caminhão aponta indícios da mediação psicofísica. A aluna 6 fez referência ao cotidiano dela ou ao senso comum para relacionar a carga elétrica ao peso, ou seja, a carga elétrica é uma propriedade da partícula e o peso está relacionado com a capacidade de transporte de carga do caminhão. Essa situação reflete a mesma descrita por Furió, Guisasola e Almudí (2004), onde os alunos utilizam o senso comum, no qual as explicações possuem falta de consistências e interpretações científicas para descrever os fenômenos relacionados a eletrostática.

Figura 3: Aluna 6: (I) Gesto \#CP: Carga e o Ponto; (II) Gesto \#CD: Caminhão se deslocando; (III) Gesto \#P: Peso.

Recebido em: 12/01/2020

Aceito em: $31 / 08 / 2020$ 


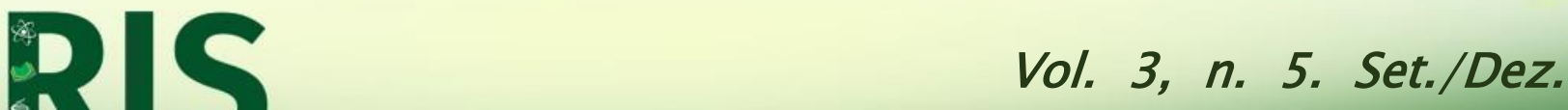

ISSN: 2595- 4520
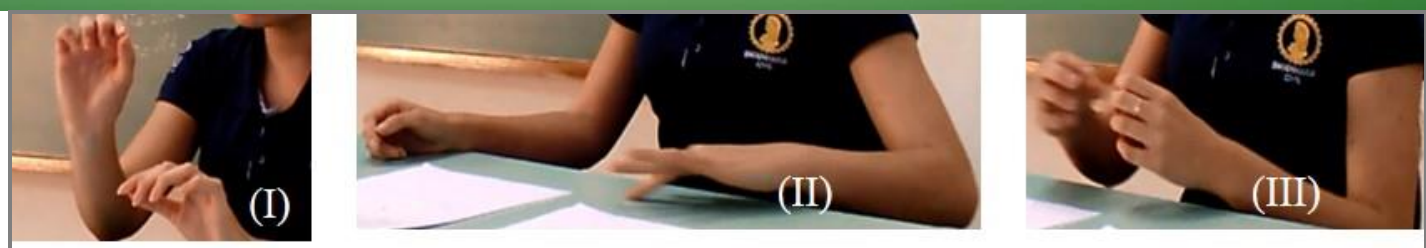

Fonte: Meggiolaro (2019).

(I)\#CP: Carga e o Ponto: com a mão fechada, os dedos aproximados, a aluna representa a carga pequena; (II) (II) \#CD: Caminhão se deslocando: representa o movimento de um caminhão se deslocando;

(III) \#P: Peso: com as mãos, representa que a carga possui um valor, semelhante ao peso de um objeto.

A aluna 6 menciona sobre a situação-problema do pré-teste, dizendo que, quando solicitada a atribuir um valor para a carga, pensou em apenas colocar valores aleatórios que variassem de zero a 10: "eu só lembrava que a unidade era C", unidade fundamental determinada pelo Sistema Internacional de Medidas - S.I, sendo C Coulomb. Ela alega que não havia parado para pensar sobre a quantidade da carga: "eu não tinha parado para pensar, na verdade”. Porém, após a realização da simulação computacional, (mediação hipercultural), diz: “eu parei para pensar”, constatando "que a carga era algo muito pequeno, então, ela é uma carga nanômetro" (Figura 4). A aluna 6 , com os dedos juntos, representa que a carga é pequena, utilizando a grandeza nano.

Figura 4: Aluna 6: Gesto \#CP: Carga e ponto.

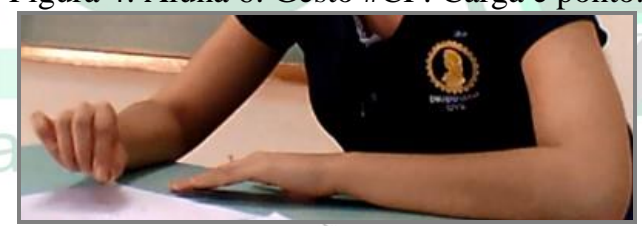

Fonte: Meggiolaro (2019).

\#CP: Carga e o ponto: com a mão fechada e os dedos aproximados, a aluna representa a carga pequena.

Consideramos que, após a simulação computacional, a aluna 6 recordou a quantidade da carga elétrica, visto que, quando questionada sobre o que se embasou para pensar na carga ser pequena, respondeu: "nos conteúdo da aula [...] Da aula de Física, [...] na aula, quando explica, quando é passado o conteúdo, depois a gente vai fazer os exercícios”. Esses são indícios da mediação cultural por tratar-se de conteúdos da aula e de mediação social por haver relação com a aula de Física.

O conceito-em-ação da aluna 6, já considerando-se o seu discurso verbal e gestual combinados, refere-se que carga tem um número associado à massa, tal qual objetos macroscópicos apresentam, e que é movimentada no espaço. Carga, para ela é efetivamente um caminhão que transporta uma massa (embora minúscula). O teorema-

Recebido em: 12/01/2020

Aceito em: $31 / 08 / 2020$ 
em-ação referente ao comportamento da carga elétrica é que "cargas são transportadas tal qual, massas são transportadas por uma distância".

$\mathrm{O}$ aluno 7 descreve que uma carga elétrica pode ter "excesso de elétrons ou falta de elétrons" e que, "se as duas têm falta ou excesso, elas não vão interagir; contrário se fosse uma carga positiva ou negativa. Uma tem, a outra não tem". "Qualquer coisa tem carga", e "é como a propriedade, tem um material ou uma partícula, [...] de cada um”. Durante a entrevista, quando questionado sobre onde encontramos cargas elétricas, ele diz:

Aluno 7: Ah, tipo, um bastão assim, vamos dizer que tem bastante nos livros...

Pesquisadora: Ótimo. Tu te lembras de algum livro em que tenha visto isso? Aluno 7: É, eu lembro uma foto, meio por cima, uma coisinha (Figura 5I) com uma bolinha (Figura 5II), assim, cheio de carguinha (Figura 5III e 5IV), assim.

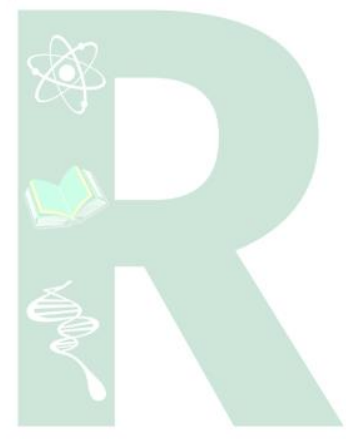

Pesquisadora: Ótimo. Tu lembras que livro é esse? Em que livro tu viu essa imagem?

Aluno 7: Do livro, eu não me lembro.

Pesquisadora: Sim, mas tu estudou isso quando? Agora, ou quando fazia Física no ensino médio?

Aluno 7: No ensino médio.

Pesquisadora: Ensino médio, a fotinho do bastão com..?

Aluno 7: Isso, com uma bolinha assim (Figura 6).

Pesquisadora: Do livro, tu não te lembra?

Aluno 7: Parecia um ovo, assim...

Pesquisadora: Sim, com os sinaizinhos.

Aluno 7: Amarelo.

Figura 5: (I)Bastão; (II) esfera condutora; (III e IV) cargas ao redor de uma esfera

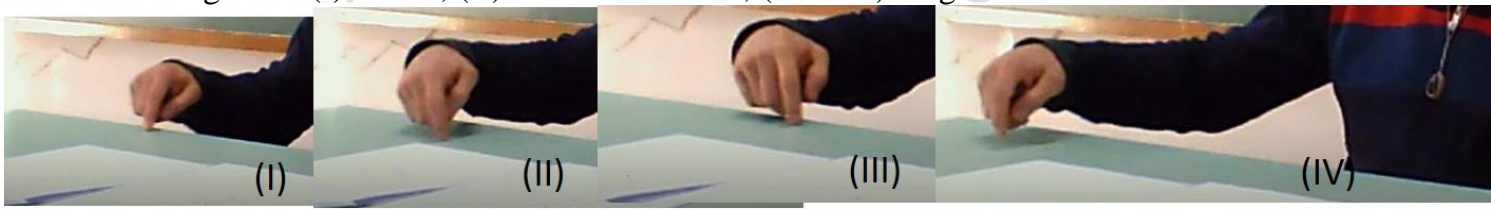

Fonte: Meggiolaro (2019).

\#BC: Bastão com cargas: representa com o dedo o bastão, com uma esfera e ao seu redor cheio de cargas.

Figura 6: Representação de uma esfera

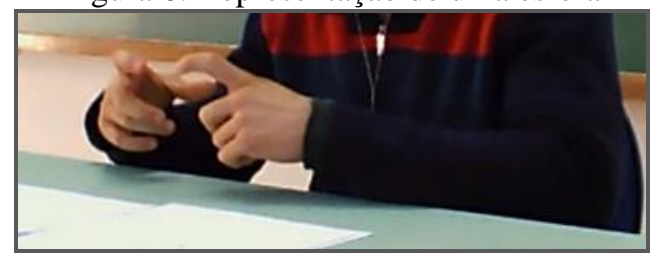

Fonte: Meggiolaro (2019).

\#E: Esfera: indica com o movimento do dedo uma esfera condutora conectada a um bastão.

Recebido em: 12/01/2020

Aceito em: $31 / 08 / 2020$ 
Provavelmente, a imagem mental que o aluno 7 descreve é semelhante à da figura 7, com o bastão, e, na extremidade, uma bolinha com cargas ao seu redor representação clássica nos livros de Física, referente os processos de eletrização por contato ou por indução. Observamos que o estudante utilizou imagens mentais culturais, como o livro, para explicar a carga elétrica. E mediação Social, referindo a Física do Ensino Médio.

Figura 7: Bastão com cargas.

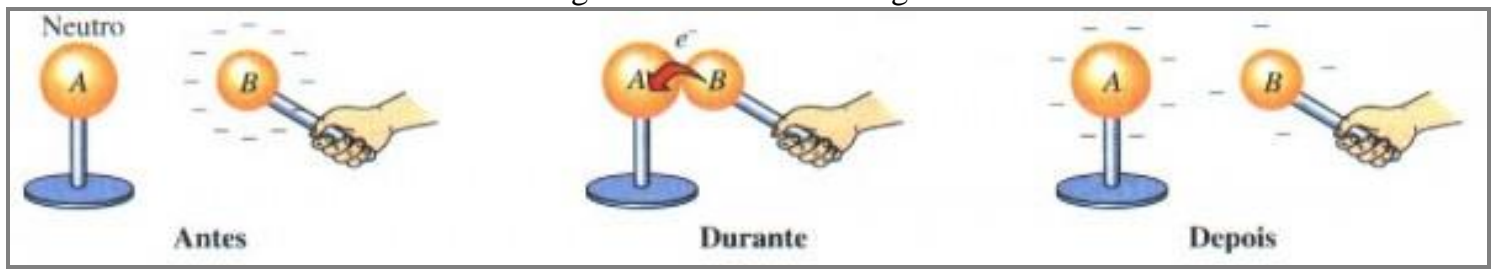

Fonte: SILVA. Disponível em: 〈https://www.infoescola.com/eletrostatica/eletrizacao/>

Medeiros e Medeiros (2002), apontaram que os alunos possuem dificuldades em compreender as representações visuais que os livros abordam, por mais que os livros apresentem situações iniciais e finais de um processo por uma série de gravuras em diferentes instantes de tempo. Porém o aluno 7, conseguiu contextualizar a atividade experimental descrita no material didático e a utilizou como um mecanismo externo para a explicação, mesmo após ter realizado a simulação computacional no GeoGebra.

O conceito-em-ação do aluno 7 para carga é que as cargas são o que provocam a eletrização por meio de eletricidade estática, visualmente associando a minúsculos sinais de carga em volta de objetos macroscópicos, tal como expostos em livros didáticos no conteúdo de eletricidade estática. Já seus teoremas-em-ação poderiam ser enunciados como "cargas iguais não interagem (contextualmente visto na sua entrevista referindo-se a linhas de campo elétrico que não se conectam) e cargas contrárias interagem (linhas de campo entre cargas contrárias), (Figura 8).

Recebido em: $12 / 01 / 2020$

Aceito em: $31 / 08 / 2020$ 
Figura 8: Linhas de campo gerado por cargas iguais.

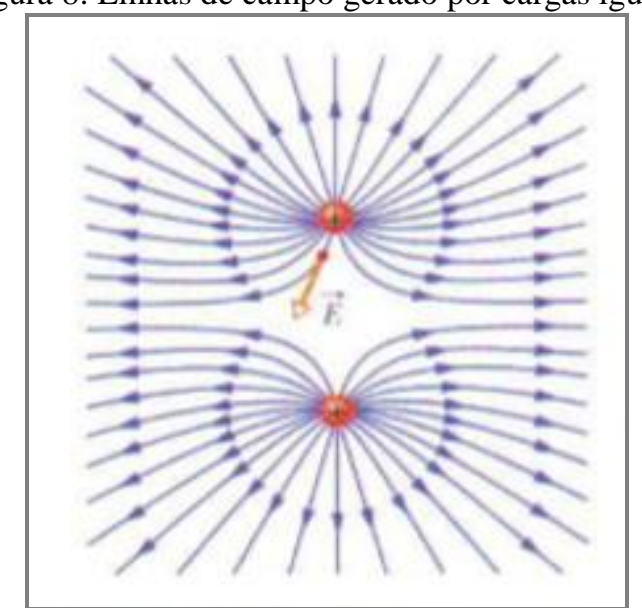

Fonte: HALLIDAY; RESNICK e WALKER, 2010, p. 24.

A aluna 8 presenta gestos referindo-se a imagem mental semelhante aos da aluna 6 (Figura 9), demonstrando que a carga é pequena.

Figura 9: Aluna 8: Gesto \#CPP: Carga pequena.
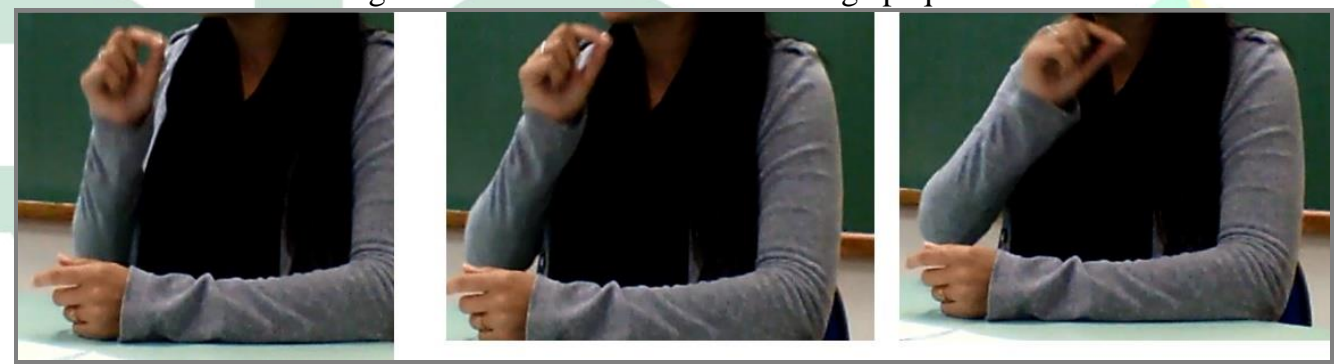

Fonte: Meggiolaro (2019).

\#CPP: Carga pequena: Representação fechando a mão, juntando os dedos que a carga é algo pequeno e microscópico.

Mas para explicar sobre a carga, a aluna 8 relaciona com campo elétrico: “[...] carga pode ser um valor de um elétron, está num campo, lá”, "o que está dentro do campo", imagina sendo "um bichinho, acho" - ela faz o movimento com a mão fechada como se estivesse pulando (Figura 9) a mediação psicofísica como foco de análise deste trabalho, uma vez que pela TMC esse conceito sobre o elétron foi construído culturalmente. Acreditamos que ela estava pensando na representação da figura 9, no dia em que a entrevista foi realizada, estávamos em uma aula sobre corrente elétrica e resistência, cujos slides apresentavam uma animação em que, os portadores de carga se movimentavam (mediação cultural).

Recebido em: 12/01/2020

Aceito em: $31 / 08 / 2020$ 


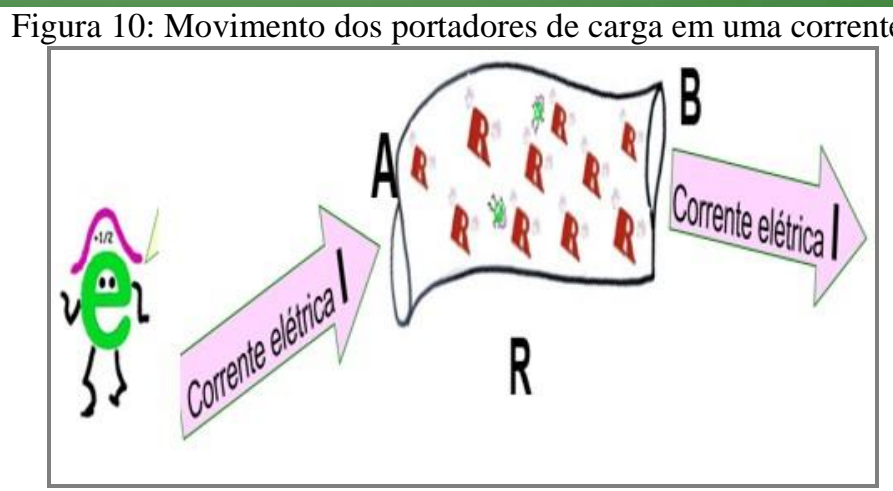

Fonte: Resistência e Corrente.

O conceito-em-ação da aluna 8 para carga elétrica é um "bichinho" ou um "portador de carga", muito pequeno. Fortemente influenciada pelo contexto da aula, que imediatamente antecedeu o momento da entrevista (aula sobre corrente e resistência). Já seu teorema-em-ação é que, cargas produzem campos elétricos.

A aluna 9 também faz referência a carga sendo minúscula e associa a atividade experimental desenvolvida em sala de aula “[...] eu acho que ela é muito minúscula, não é? Então, quando tem aquele negócio da caneta” (Figura 11), "quando tu faz na caneta... É um negócio por causa das cargas, então, provavelmente, tem mais alguma coisa".

$\mathrm{Na}$ atividade relatada pela aluna, a professora levou um canudinho e pedaços de papel, onde friccionaram o canudo no cabelo, deixando esse objeto eletricamente carregado, assim exercendo uma força sobre os pedaços de papel. Acreditamos que a mediação é psicofísica para o foco de análise deste trabalho em relação à atividade, porém pela TMC essa experiencia foi construída culturalmente, e social, porque lembra a aula de Física $\mathrm{C}$.

Figura 11: Aluna 9: Gesto \#PE: Processo de Eletrização.

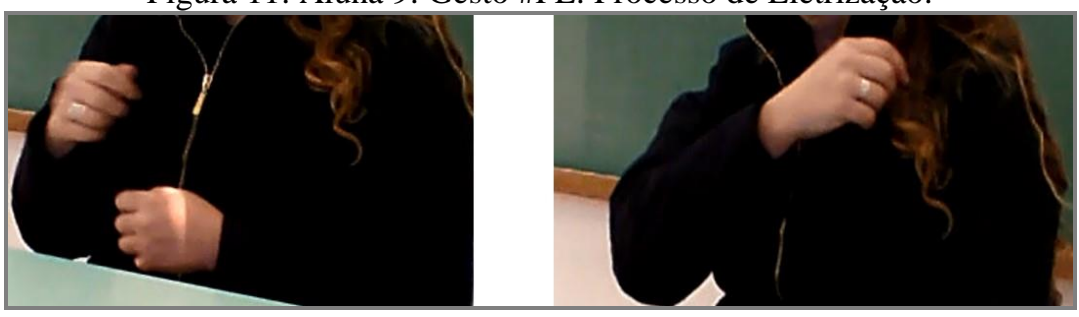

Fonte: Meggiolaro (2019).

\#PE: Processo de eletrização: com a mão, a aluna simula que está aproximando a caneta do cabelo, carregando.

A respeito do depoimento da aluna 9, concordamos com Laburú, Silva e Zõmpero (2015) onde é viável analisar as ações exteriorizadas pelos alunos em relação aos 
conceitos científicos, porém é preciso que o professor analise com outras representações, como as verbais.

O teorema-em-ação utilizado pela aluna 9 , dentro da situação-problema relacionado a carga elétrica está associado as cargas estarem presentes no processo, enquanto seus conceitos-em-ação refere-se a carga e processo de eletrização.

Por fim, é interessante observar que os indícios levantados dos cinco alunos em relação ao conceito de carga elétrica estão relacionados à apropriação de diferentes mecanismos externos para aplicar na situação-problema solicitada, uma vez que cada aluno/indivíduo internaliza este conceito de acordo com seus interesses.

\section{CONCLUSÃO}

A exploração das situações-problema, no qual elas se entrelaçaram com os mecanismo externos de mediação no domínio do campo conceitual da eletrostática, na análise sobre a carga elétrica, concluímos que o uso articulado dos mecanismos externos de mediação psicofísico, cultural, social e hipercultural revelou-se importante, porém a mediação social sobressaiu-se na aprendizagem do conceito de carga elétrica, apontada por quatro alunos.

A interpretação dos gestos forneceu informações que não foram identificadas apenas por intermédio da fala, uma vez que constatamos nas análises a importância da associação gestual e verbal na transmissão de informações, sendo que através da gesticulação foi viável analisar as ações exteriorizadas pelos alunos em relação aos conceitos de carga elétrica.

A utilização de imagens mentais foram apontadas nas análises dos cinco alunos através de fortes indícios das informações subtendidas na memória, sendo formas de representações mentais em que os alunos utilizaram para representar internamente o mundo externo.

Sendo assim, as Teorias Construtivistas da Mediação Cognitiva e dos Campos Conceituais se mostraram eficazes para o estudo sobre a Eletrostática, cuja ligação entre as teorias está nas relações dinâmicas entre os elementos que compõem o espaço das suas interações com o ambiente. O vínculo das teorias está em um conceito que não se forma dentro de um só tipo de situação, e os alunos, quando questionados nas entrevistas, relataram diversas mediações em uma situação, fazendo integração entre as partes e apontando uma construção do campo conceitual da Eletrostática. Os 
mecanismos externos de mediação (TMC) entrelaçam-se com as situações-problema (TCC) nas variadas situações em que um conceito se torna significativo, o sentido não está nas palavras nem nos símbolos, mas nas relações que os alunos fazem.

Dentro desta perspectiva, este trabalho avança a discussão sobre o Ensino de Física por meio de dispositivos hiperculturais e se torna um contraponto, com o intuito de ampliar a discussão referente aos conceitos de Eletrostática, em que a presença do professor em sala de aula é importante, e a utilização de recursos computacionais auxilia na visualização de elementos complexos e na movimentação, permitindo que o aluno analise, conjecture e estabeleça hipóteses. Para que tenhamos uma aprendizagem que contemple a todos os alunos, segundo nossa investigação é necessário proporcionar diferentes mecanismos de mediações externos dentro do estudo de um conceito de Física, tanto na Educação Básica quando no Ensino Superior para que torne possível a conexão de estruturas externas como auxiliares de dispositivos de processamento de informações.

\section{REFERÊNCIAS}

BASER, M.; GEBAN, O. Effect of instruction based on conceptual change activities on students' understanding of static electricity concepts. Research in Science \& Technological Education. v. 25, 2. ed., 2007.

CLEMENT, J. J.; STEPHENS, A. L. Documenting the use of expert scientific reasoning process by high school physics students. Physics Education Research, v. 6, n. 2, p. 20122-1-20122-15, 2010.

DA SILVA, W.; ASSIS, A.; TRAVAIN, S. Função Quadrática e Lançamento Oblíquo: proposta de uma abordagem investigativa. Revista Insignare Scientia - RIS, v. 3, n. 2, p. 334-348, 25 ago. 2020.

DORI, Y; BELCHER J. How Does Technology-Enabled Active Learning Affect Undergraduate Students' Understanding of Electromagnetism Concepts?. The Journal of the Learning Sciences. v. 14, 2. ed., 2005.

ERICKSON, F. Qualitative methods in research on teaching. In M. C. Wittrock, Handbook of research on teaching. New York: MacMillan, p. 162-213. 1986.

FURIÓ C.; GUISASOLA J.. Dificultades de aprendizaje de los conceptos de carga y de campo eléctrico en estudiantes de Bachillerato y Universidad. Enseñanza de Las Ciencias. 16(1), p. 131-146, 1998.

FURIÓ, C.; GUISASOLA, J.. La enseñanza del concepto de campo eléctrico basada en un modelo de aprendizaje como investigación orientada. Enseñanza de Las Ciencias. 19(2), pp. 319-334, 2001.

Recebido em: $12 / 01 / 2020$

Aceito em: $31 / 08 / 2020$ 
FURIÓ, C.; GUISASOLA, J.; ALMUDÍ, M.. Elementary Electrostatic Phenomena: Historical Hindrances and Students' Difficulties. Canadian Journal of Science, Mathematics and Technology Education. 4(3), p. 291-313, 2004.

FURIÓ, C.; GUISASOLA, J; ALMUDÍ, M; CEBERIO, M... Learning the electric field concept as oriented reserarch activity. Science \& Education. p. 640-662, 2002.

GAGNON, M.. The use of computer-simulated trajectories to teach real particle flight. Phisics Education. 2011.

GIRE, E. Arrows as anchors: An analysis of the material features of electric field vector arrows. Physical review special topics. 10, 020112, 2014.

GUISASOLA, J; FURIÓ, C.. Difficulties in Learning the Concept of Electric Field. Science \& Education, 1998.

GUISASOLA, J.; ZUBIMENDI, J.; ALMUDÍ, J.; CEBERIO, M.. Dificultades persistentes en el aprendizaje de la electricidad: Estrategias de razonamiento de los estudiantes al explicar fenómenos de carga eléctrica. Enseñanza de Las ciencias. 26(2), p. 177-192, 2008.

GUPTA, A.; HAMMER, D.; REDISH, E. The case for dynamic models of learner's ontologies in physics. Journal of Learning Sciences. v. 19, 3. ed., 2010.

HALLIDAY, D.; RESNICK, R. WALKER, J. Fundamentos de física, volume 3: eletromagnetismo. Jearl Walker: tradução e revisão técnica Ronaldo Sérgio de Biasi. Rio de Janeiro: LTC. 2010.

LABURU, C.; SILVA, O.; ZÔMPERO, A. Significados de eletrostática interpretados por meio da gesticulação de estudantes. Ciência e Educação (Bauru). v.21 n.4 Bauru. 2015.

LOPEZ, E; SILVA, R. Transformación de los modelos mentales sobre los conceptos de fuerza y campo eléctrico mediante la metodología WebQuest, en estudiantes universitarios de Ingeniería. Caderno Brasileiro de Ensino de Física, v. 32, n. 1, p. 2$31,2015$.

MARTIN, J.; SOLBES, J.. Diseño y evoluación de una propuesta para la enseñanza del concepto de campo en Física. Enseñanza de las ciencias, v. 19, n. 3, p. 393-403, 2001.

MEDEIROS, A.; MEDEIROS, C. Possibilidades e Limitações das Simulações Computacionais no Ensino da Física. Revista Brasileira de Ensino de Física, v. 24, n. 2, Junho, 2002.

MEGGIOLARO, G. Uma investigação entre os mecanismos de mediação externa e as situações-problema, no estudo do campo conceitual da eletrostática com estudantes da engenharia. (Tese de doutorado, Universidade Luterana do Brasil, Canoas, 2019). Tese de Doutorado em Ensino de Ciências e Matemática, 187f.

MORAES, R.; GALIAZZI, M. C. Análise Textual Discursiva. Ijuí: Editora Unijuí, 2007.

Recebido em: 12/01/2020

Aceito em: $31 / 08 / 2020$ 
MONAGHAN, J. M.: CLEMENT, J.J. Use of a computer simulation to develop mental simuations for understanding relative motion concepts. International Journal of Science Education. v. 21, n. 9, p. 921-944. 1999.

PERIAGO, M.; BOHIGAS, X. A study of second-year engineering students' alternative conceptions about electric potential, current intensity and Ohm's law. European Journal of Engineering Education. v.30, 1.ed, 2005.

RAMOS, A. F. Estudo do Processo de Internalização de Conceitos de Química Utilizando Software de Modelagem Molecular: Uma proposta para o ensino médio e superior. 2015. 230 f. Tese (Doutorado - Ensino de Ciências e Matemática), Universidade Luterana do Brasil, Canoas, 2015.

ROCHA, J; ANDRADE NETO, A. Um Estudo de Caso Exploratório sobre a Internalização de Conceitos sobre Eletrostática: A influência da Hipercultura e Mediação Digital. Revista Novas Tecnologias na Educação - RENOTE. v. 11 n. 3, dezembro, 2013.

SANTOS, A. V; SANTOS, S. R.; FRAGA, Luciane M. Sistema de Realidade Virtual para Simulação e Visualização de Cargas Pontuais Discretas e seu Campo Elétrico. Revista Brasileira de Ensino de Física, v. 24, n. 2, Junho, 2002.

SERWAY, R. JEWETT, J. Princípios de física: eletromagnetismo. São Paulo: Cengage Learning, 2008.

SILVA, A. Eletrização. InfoEscola. Disponível em: https://www.infoescola.com/eletrostatica/eletrizacao/ Acesso em: 17 junho 2018.

SOUZA, B. C. A Teoria da mediação cognitiva: os impactos cognitivos da hipercultura e da mediação digital. Tese (Doutorado em Psicologia Cognitiva), Programa de Pós-graduação em Psicologia, Universidade Federal de Pernambuco, Recife, 2004.

SOUZA, B. C.; LULA, A. M.; MOURA, A. L. N. O papel da hipercultura na atividade de consultoria: um estudo com consultores na Região Metropolitana do Recife. In: XXXVI Encontro da ANPAD. Anais. Rio de Janeiro, 2012.

TREVISAN; R. O estudo da relação entre as imagens mentais utilizadas por estudantes de mecânica quântica e seu perfil epistemológico: uma investigação pela metodologia Report Aloud. 2016. 143f. Dissertação (Mestrado) - Ensino de Ciências e Matemática, Universidade Luterana do Brasil, Canoas, 2016.

TREVISAN, R.; ANDRADE NETO, A. S.; WOLFF, J. F. S. ; RAMOS, A. F. . Peeking into their minds: the Report Aloud technique as a means of identifying student's mental imagery. Ciência e Educação (UNESP), 2019.

TAO, P. K.; GUNSTONE, R. F. A process of conceptual change in force and motion during computer-supported Physics instruction. Journal of Research in Science Teaching, v.3 7, n. 2, p. 859-882, 1999.

Recebido em: $12 / 01 / 2020$

Aceito em: $31 / 08 / 2020$ 
VELOSO; M. S. O. Uma investigação do processo de (re)construção de conceitos de Física em atividades experimentais em cursos de Física a distância. 2017. 206f. Tese (Doutorado)- Ensino de Ciências e Matemática, Universidade Luterana do Brasil, Canoas, 2017.

VERGNAUD, G. La théorie de champs concepyuels. Recherches em Didactique de Mathématiques. Grenoble: La Pensée Sauvage. v. 10. 1990.

WOLFF, J. F. S. As modificações de drivers prévios através da utilização de simulações computacionais: aprendizagem significativa dos conceitos de colisões verificadas através da análise das imagens mentais de estudantes universitários. 2015. 260 f. Tese (Doutorado) - Ensino de Ciências e Matemática, Universidade Luterana do Brasil, Canoas, 2015.

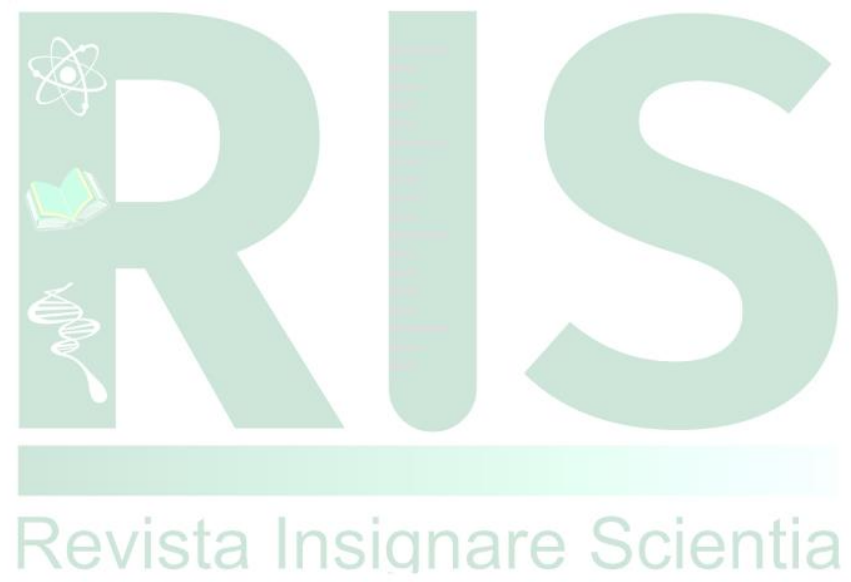

Recebido em: 12/01/2020

Aceito em: $31 / 08 / 2020$ 